\title{
Experience of temporary cardiac pacing in a district general hospital
}

\author{
KENNETH R. PATERSON* \\ M.B., Ch.B., M.R.C.P. \\ Royal Alexandra Infirmary, Paisley
}

\begin{abstract}
Summary
Temporary cardiac pacing is widely used in the management of dysrhythmias; increasingly it is being employed in district general hospitals without specialist cardiology facilities. A retrospective study of 117 pacing procedures in a district hospital has shown that temporary pacing is both safe and effective and supports its more widespread use.
\end{abstract}

KEY WORDS: myocardial infarction, cardiac arrhythmias.

\section{Introduction}

Temporary cardiac pacing in the management of both tachydysrhythmias and bradydysrhythmias is a recognized part of modern cardiological practice-its efficacy and safety are widely accepted. Most studies have been conducted in cardiology units staffed by specialist cardiologists. I have looked retrospectively at the experience of temporary cardiac pacing in a district general hospital staffed by 4 consultant physicians, and $4 \mathrm{SHO} /$ registrars graded according to experience.

\section{The study}

The Royal Alexandra Infirmary, Paisley, is a district general hospital serving a mixed urban and rural population of 210,000 . A 4-bedded Coronary Care Unit was opened in 1971 and throughout the study period it was policy to admit all patients aged 70 years or less with suspected acute myocardial infarction. In addition, a very few patients older than 70 years were transferred to the Coronary Care Unit from the general medical wards for specialized management of dysrhythmias. Temporary pervenous cardiac pacemaker insertion for the management of dysrhythmias was introduced in 1972 . Initially, radiological screening of catheter insertion necessitated transfer to the radiology department but, from mid1974, a portable image intensifier (GEC Cardiovi-

\footnotetext{
*Present address: Medical Unit, Glasgow Royal Infirmary, Castle Street, Glasgow G4 OSF.
}

sion) was available in the Coronary Care Un making fluoroscopy safer for the patient and easiogr for the staff.

I have studied all the pacing procedures performed up to August 1981, obtaining details from case-shees and Coronary Care Unit records.

\section{Methods}

Bi-polar temporary pacing catheters (USCI, $5 \mathrm{~F}_{\frac{\mathbb{T}}{\mathrm{T}}}$ $6 \mathrm{~F}, 125 \mathrm{~cm}$ ) were usually inserted via the left median basilic vein. A battery-powered demand pacemak pulse generator (Devices Ltd) provided the paofing stimulus. An intravenous cannula was sited insthe right arm but anti-dysrhythmic therapy wasọnfot routinely given before or during pacemaker insertiog.

The procedure was normally performed by the 'oncall' SHO/registrar with assistance from one or tw如 nurses. When the catheter had been sited, oral broasspectrum antibiotic cover (ampicillin) and intravnous heparin $(30,000$ iu daily) were given and continued until removal of the catheter. The paciog threshold was checked daily and the stimulus voltage set to approximately twice the threshold. The temporary pacing catheter usually remained in situ untila stable sinus rhythm had been present for $48 \mathrm{hr}$ or permanent pacemaker unit was fitted.

\section{Results}

Between May 1974 and August 1981, 117 pace maker procedures were attempted by 18 operators to 17 procedures each). The average radiologicat screening time was 18 mins. There was evidence $8 \mathrm{f}$ recent myocardial infarction in 94 patients while had no evidence of recent infarction by eithes electrocardiographic or enzyme criteria. Those witbout recent infarction were significantly older (mean 69.2 years, s.d. 14.2) than those with a recegt myocardial infarction (mean 62.3 years, s... 9.9) $-P<0.01$, 2-tailed Student's $t$-test. 


\section{Myocardial infarction}

Successful temporary cardiac pacing was achieved in 84 patients with acute myocardial infarction; pacing was technically unsuccessful in 6 patients and a further 4 died during the pacemaker insertion. The indications for temporary pacemaker insertion in these 94 patients are shown in Table 1. The site of infarction and outcome of hospitalization in the 84 patients in whom pacemaking was achieved are shown in Table 2.

TABLE 1. Indications for pacemaker insertion in 94 patients with myocardial infarction

\begin{tabular}{lc}
\hline & Number of patients \\
\hline Established complete heart block & 73 \\
Intermittent complete heart block & 3 \\
Second degree heart block & 9 \\
'Sick sinus' syndrome & 3 \\
Sinus/nodal bradycardia & 3 \\
Tachydysrhythmia & 3 \\
\hline
\end{tabular}

The average duration of temporary pacing in patients eventually returning to sinus rhythm was 6.6 days. Thirty-six patients who were successfully paced died in hospital-32 died in the Coronary Care Unit, the great majority within $24 \mathrm{hr}$ of pacemaker insertion. Four patients died in the general wards following removal of the pacemaker; 3 died suddenly, presumably due to dysrhythmia, and 1 died of acute renal failure following prolonged hypotension after the acute infarction.

Of the 6 patients in whom adequate temporary pacing was not achieved, 3 reverted to sinus rhythm, 1 required a permanent pacemaker and 2 died, both within $24 \mathrm{hr}$ of the failed pacemaker insertion.

\section{No myocardial infarction}

Pacemaker therapy was indicated in 18 of these 23 patients for complete heart block. In 2 others, complete heart block was intermittent and 3 had other dysrhythmias. Successful pacing was achieved in 17 patients while pacing was unsuccessful in 6 (Table 3). Four patients returned to sinus rhythm-2 had been treated for resistant tachydysrhythmias which eventually responded to medical measures and
2 had a short period of complete heart block which reverted to sinus rhythm and remained as such for over one year of follow-up.

TABLE 3. Outcome of pacemaker therapy in patients without myocardial infarction

\begin{tabular}{lcc}
\hline & $\begin{array}{c}\text { Successful } \\
\text { pacing }\end{array}$ & $\begin{array}{c}\text { Unsuccessful } \\
\text { pacing }\end{array}$ \\
\hline Reversion to sinus rhythm & 3 & 1 \\
Permanent pacemaker & 13 & 4 \\
Died & 1 & 1 \\
Total & 17 & 6 \\
\hline
\end{tabular}

\section{Complications of pacemaker therapy}

The complications of pacemaker insertion and therapy are shown in Table 4. All the dysrhythmias during catheter insertion occurred as the tip of the catheter crossed the tricuspid valve to enter the right ventricle and all responded to DC cardioversion or drug therapy (intravenous lignocaine or verapamil). The pacemaker insertion procedure was then continued and adequate pacing was subsequently achieved in all the patients-further anti-dysrhythmic therapy was not required.

TABLE 4. Complications of pacemaker therapy-all patients

\begin{tabular}{ll}
\hline Complication & Number of patients \\
\hline $\begin{array}{l}\text { Ventricular tachycardia/fibrillation } \\
\text { during pacemaker insertion }\end{array}$ & 6 \\
$\begin{array}{c}\text { Supraventricular tachycardia } \\
\text { during pacemaker insertion }\end{array}$ & 1 \\
$\begin{array}{l}\text { Ventricular tachycardia/fibrillation } \\
\text { during demand pacing }\end{array}$ & 6 \\
$\begin{array}{l}\text { Catheter repositioning/change required } \\
\text { Local infection/phlebitis at catheter }\end{array}$ & 6 \\
$\begin{array}{l}\text { insertion site } \\
\text { Pulmonary embolic disease }\end{array}$ & 5 \\
Brachial artery cannulated & 1 \\
\hline
\end{tabular}

Six patients developed ventricular tachycardia during demand pacing, presumably due to failure of the catheter to sense spontaneous ventricular beats. Only one patient was not successfully resuscitated by DC cardioversion. Following the ventricular tachycardia, 2 patients remained on fixed-rate pacing at

TABLE 2. Outcome of pacemaker therapy in 84 patients according to site of myocardial infarct (percentage in brackets)

\begin{tabular}{lrccc}
\hline & $\begin{array}{c}\text { Inferior } \\
(n=54)\end{array}$ & $\begin{array}{c}\text { Anterior } \\
(n=24)\end{array}$ & $\begin{array}{c}\text { Unknown site } \\
(n=6)\end{array}$ & $\begin{array}{c}\text { Overall } \\
(n=84)\end{array}$ \\
\hline Reversion to sinus rhythm & $36(67)$ & $9(38)$ & $1(17)$ & $46(55)$ \\
Permanent pacemaker & $0(0)$ & $2(8)$ & $0(0)$ & $2(2)$ \\
Died & $18(33)$ & $13(54)$ & $5(83)$ & $36(43)$ \\
\hline
\end{tabular}


100 beats/min for several hours to prevent further interference between the pacemaker and their spontaneous rhythm.

Six patients who had been successfully paced ceased to respond to the pacing stimulus, all within $48 \mathrm{hr}$ of catheter insertion. In 3 of these patients, the initial placement of the catheter had been imperfect but the patients had developed ventricular standstill when re-siting was attempted and imperfect positioning was accepted. When adequate pacing ceased, catheter positioning was checked radiologically and, if apparently satisfactory, the pacing voltage was increased in an effort to regain pacing. This was unsuccessful and repositioning of the catheter was required in 4 patients. In the other 2 , the pacing catheter had to be replaced to achieve adequate pacing.

In addition to direct complications of pacing, 2 patients developed pericarditis following an acute infarction and a further 3 developed a post-myocardial infarction syndrome. Ventricular perforation was not recognized clinically in any patient, however few of the patients who died underwent post-mortem examination.

\section{Discussion}

When atrio-ventricular block associated with haemodynamic upset complicates acute myocardial infarction, the mortality without treatment is high (Julian, Valentine and Miller, 1964; Kitchen and Kastor, 1975). The introduction of pacemaker therapy has reduced this (Kitchen and Kastor, 1975; Lassers and Julian, 1968; Sutton, Chatterjee and Leatham, 1968; Watson and Goldberg, 1971). Initially, pacemaker insertion was restricted to specialized cardiology departments but increasingly the technique has been applied in smaller district and community hospitals without specialist cardiology facilities (Kwan, 1969; Northcutt, Morgan and Ligon, 1975; Bartecchi, 1976; Fairbanks et al., 1977; Kashiwagi et al., 1978; Coder, 1978).

The indications for temporary pacemaker insertion following acute infarction are broadly agreed (Kitchen and Kastor, 1975; Hayward, 1981). The 94 patients studied fulfil recognized criteria for pacemaker therapy. The results confirm the higher mortality in patients with anterior infarction and the overall mortality is similar to previously quoted studies (Lassers and Julian, 1968; Sutton et al., 1968; Watson and Goldberg, 1971; Tucker et al., 1973).

The majority of patients with complete heart block in the absence of recent infarction will require permanent pacing. If this cannot be provided locally, a delay may arise and, in this study, it was usual to insert a temporary pacing catheter in any patient

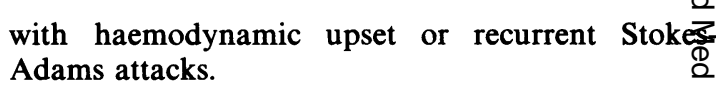

Twelve attempted pacemaker insertions were ufrsuccessful, either due to inability to advance the catheter into the heart or inability to achieve $f^{a}$ satisfactory pacing stimulus. Most of these failutes occurred in the initial 2 years when experience of the technique was still being gained. The adoption of $t$ ge subclavian or internal jugular venous routes migft further reduce the technical problems of catheterization though these routes are more hazardous inexperienced hands (Lassers and Julian, 1968). The incidence and type of complications were similar $\overrightarrow{\text { go }}$ reported complications in other series (Sutton et $\mathscr{P}$, 1968; Watson and Goldberg, 1971; Lumia and Ri\&, 1973). Routine antibiotic prophylaxis was givęn though this practice is not followed in all centres. $\subseteq$

A questionnaire survey of 9 district hospitas around Glasgow showed that all are performiffy temporary cardiac pacings, in either the Coronagy Care Unit or radiology department. The length $\& f$ experience of pacemaker therapy is variable $p_{3}$ months- 12 years) but the reports suggest that abougt 190 temporary pacing procedures are performed annually in the district hospitals in the West of Scotland.

Major disturbances of cardiac rhythm are poteentially fatal and their management, by whater means, should be in the hospital of first refergl wherever possible. Temporary cardiac pacin is technically possible in almost any district hospital providing Coronary Care facilities. The image intersifier is the major item of expenditure which, onge obtained, can often find other uses (e.g., colonoscopor, lymphangiography) to offset the high initial cost. Pacing catheters and pulse generators are relativety inexpensive and the other equipment required $\exists$ s already available in most district hospitals.

If facilities for temporary pacing are available in district hospital then only a few patients will requime transfer to a cardiology centre-these will inclu裉 patients requiring more specialized techniques (e $\bar{g}$. intra-atrial pacing), those requiring specialized inves:tigation (e.g. His-bundle conduction studies) and åy in whom attempted pacing has been unsuccessfi. Permanent pacemaker insertion will also necessitafe transfer to a specialized unit.

The results presented show that temporary pace. maker insertion in a district hospital has proved to a safe and effective procedure and that its continued, and indeed wider, use is justified.

\section{Acknowledgments}

Thanks are due to Drs H. Conway, S.G. McAlpine, J. Williams and T.I. McBride, Consultant Physicians, for permission to report:on patients under their care and for their help in the preparation of thits 
paper. I also acknowledge the work of my fellow registrars whose efforts I have recorded.

\section{References}

BARTECCHI, C.E. (1976) Bedside emergency transvenous cardiac pacing-experience in two community hospitals. JACEP, 5, 169.

CODER, D.M. (1978) Temporary cardiac pacing in a community practice. Illinois Medical Journal, 153, 27.

FAIRBANKS, W., MCMASTER, D., DZINDZIO, B.S. \& ForKer, A.D. (1977) Temporary transvenous cardiac pacemaking in rural family practice. Journal of Family Practice, 4, 641.

HAYWARD, R. (1981) Who do we pace? British Journal of Hospital Medicine, 25, 466.

Julian, D.G., Valentine, P.A. \& Miller, G.G. (1964) Disturbances of rate, rhythm and conduction in acute myocardial infarction. American Journal of Medicine, 37, 915.

KashiwaGi, M., OHKUbo, T., USUI, T., MIYAZaKI, Y. \& Kondo, K. (1978) Significance of cardiac pacing performed by physicians in a community hospital. Japanese Circulation Journal, 42, 325.

KITCHEN, J.G. \& KASTOR, J.A. (1975) Pacing in acute myocardial infarction; indications, methods, hazards and results. Cardiovascular Clinics, 7, 219.

KWAN, V.W. (1969) Transvenous pacing in the community hospital. Medical Times, 97, 173.

LASSERS, B.W. \& JULIAN, D.G. (1968) Artificial pacing in management of complete heart block complicating acute myocardial infarction. British Medical Journal, 3, 142.

LUMIA, F.J. \& Rios, J.C. (1973) Temporary transvenous pacemaker therapy: an analysis of complications. Chest, 64, 604.

NORTHCUTT, C.E., MORGAN, J.D. \& LIGON, R.E. (1975) Temporary transvenous pacemakers in the community hospital. American Family Physician, 11, 115.

Sutton, R., Chatterjee, K. \& Leatham, A. (1968) Heart block following acute myocardial infarction-treatment with demand and fixed-rate pacemakers. Lancet, ii, 645.

TuCKER, H.H., Carson, P.H.M., Bass, N.M., SharratT, G.P. \& STOCK, J.P.P. (1973) Results of early mobilization and discharge after myocardial infarction. British Medical Journal, 1, 10.

WATSON, C.C. \& GolDBERG, M.J. (1971) Evaluation of pacing for heart block in myocardial infarction. British Heart Journal, 33, 120.

(Accepted 3 March 1983) 